\title{
Estrutura de Controle das Companhias Brasileiras de Capital Aberto
}

\author{
Ricardo Pereira Câmera Leal \\ André Luiz Carvalhal da Silva \\ Silvia Mourthé Valadares
}

\section{Resumo}

O presente trabalho analisa a estrutura de controle direta e indireta de empresas brasileiras no final de 1998. Nossos resultados revelam um elevado grau de concentração de capital votante no Brasil. Mesmo nos casos em que não há um acionista controlador, o maior acionista detém uma participação significativa dos direitos sobre voto e a companhia é, geralmente, controlada por seus três maiores acionistas. Concluímos também que a utilização de pirâmides como um mecanismo para manutenção de controle a um custo menor, isto é, com investimento menor no capital total, não é muito comum. Os acionistas controladores brasileiros investem em média muito mais do que o mínimo necessário para manter o controle nas suas companhias.

Palavras-chaves: governança corporativa; controle; propriedade; acionista controlador.

\section{Abstract}

This paper analyzes the control structure of Brazilian public companies at the end of 1998 . We show a high degree of ownership concentration. Even when there is no majority shareholder, the largest one owns a significant portion of the voting capital, and the company is, on average, controlled by its three largest shareholders. We also conclude that the utilization of pyramid structures does not appear to be an effort to avoid the one share-one vote rule in Brazilian companies.

Key words: corporate governance; control; ownership; controlling shareholder. 


\section{INTRODUÇÃO}

O objetivo deste trabalho é analisar a estrutura de controle de empresas brasileiras, a partir de uma análise da concentração direta e indireta dos direitos sobre voto e fluxo de caixa dos acionistas controladores. Entende-se por direitos sobre os votos a propriedade de ações com direito a voto. O direito sobre o fluxo de caixa representa a propriedade de ações com ou sem direito a voto. Como no Brasil são utilizadas intensamente ações sem direito a voto, a regra de uma ação - um voto não é respeitada e os direitos sobre os votos não correspondem aos direitos sobre o fluxo de caixa. A participação no capital total representa os direitos sobre fluxo de caixa. A participação no capital votante representa os direitos sobre os votos. São avaliados o grau de concentração de controle das companhias juntamente com os mecanismos utilizados para separar controle de propriedade.

A compreensão da estrutura de controle é de fundamental importância, uma vez que ela influencia diretamente a eficiência do mercado por controle corporativo. Primeiramente, ela mostra o grau de diversificação de risco dos acionistas. Outro ponto importante é que ela demonstra um potencial problema de agência na gestão da firma. Pode haver um problema de agência entre a gerência e os acionistas, pois a primeira pode não estar maximizando o valor para os últimos. Quando existe um acionista que pode influenciar a gerência de uma companhia, novo problema de agência pode surgir, desta vez entre os acionistas controladores e os acionistas minoritários.

Grande parte da literatura que estudou o problema de separação entre propriedade e controle, o fez dentro de um ambiente onde a propriedade é difusa, ou seja, em ambiente marcado por grande número de pequenos acionistas, cada um com uma parcela muito pequena do capital. Berle e Means (1932), ao analisarem a estrutura de propriedade das empresas nos Estados Unidos, observaram a prevalência de empresas de capital aberto com propriedade diluída entre vários pequenos acionistas minoritários.

Poucos são os países que se caracterizam por empresas com propriedade difusa. Esta estrutura de propriedade ocorre basicamente em grandes corporações de países de tradição jurídica anglo-saxã. Países como França, Itália e Alemanha, entre outros, caracterizam-se por forte concentração de propriedade e controle. La Porta et al. (1999) apresentam evidências de que, em 27 países desenvolvidos, se observa grande concentração do controle e da propriedade das empresas nas mãos de famílias e do Estado, ao invés da propriedade difusa proposta por 
Berle e Means (1932). Em outro estudo, La Porta et al. (1998), utilizando uma amostra de 49 países, mostram que, mesmo se nos concentrarmos nas maiores companhias abertas (normalmente caracterizadas por propriedade mais difusa), os três maiores acionistas possuem, em média, 46\% da empresa.

La Porta et al. (1998) mostram uma correlação fortemente negativa entre concentração de propriedade e qualidade de proteção legal aos investidores em determinado país. Em países cuja lei não protege adequadamente os investidores, eles devem ter participações grandes o suficiente para exercerem o monitoramento dos gerentes da companhia. O Brasil pertence à tradição do direito francês, que oferece a menor proteção legal aos investidores, segundo La Porta et al. (1998); portanto é de se esperar alta concentração de capital nas empresas, principalmente no que se refere a capital votante.

Siffert Filho (1998) examina as mudanças no controle societário das empresas brasileiras nos anos 90 . O autor estuda as 100 maiores empresas não-financeiras, independentemente de o controle ser privado nacional, estatal ou estrangeiro. No caso brasileiro, o autor identifica o crescimento significativo da forma de controle compartilhado das corporações, possuindo como acionistas principalmente investidores institucionais, tanto nacionais como estrangeiros. Observa-se também o avanço significativo da presença de empresas estrangeiras e a redução daquelas cujo controle era familiar. Siqueira (1998) analisa as causas e conseqüências da concentração da propriedade das empresas brasileiras de capital aberto, com base em amostra de 278 empresas. O autor conclui que o grau de concentração do controle acionário no Brasil sofre influência da regulamentação do mercado, do tamanho da firma e da estrutura de capital.

Procianoy (1994) analisa as características das sociedades anônimas brasileiras no que se refere à legislação societária, às peculiaridades do mercado de capitais brasileiro, ao histórico de crescimento das empresas e aos fatores que têm levado seus controladores à busca de uma solução para suas sucessões. O autor identifica a existência de um grupo controlador bem definido na maior parte das empresas brasileiras, ao contrário da maioria das empresas norte-americanas. Procianoy e Comerlato (1994) concluem que a existência de grupos econômicos formados por mais de uma companhia aberta, cujo controle e gestão são exclusividade de um pequeno grupo de investidores (controladores), pode gerar conflito de interesse entre os controladores e os acionistas minoritários, ou seja, a possibilidade de que os controladores possam realizar transferências de receitas, despesas ou investimentos entre as empresas controladas, no intuito de maximizar a sua riqueza, gerando perdas para os acionistas minoritários. Hallqvist (2000) analisa os principais tópicos da governança corporativa no Brasil, abordando o Código Brasileiro das Melhores Práticas de Governança Corporativa. 
Valadares e Leal (2000) avaliaram a estrutura de propriedade e controle de companhias de capital aberto no Brasil listadas na Bolsa de Valores de São Paulo (BOVESPA) em dezembro de 1996. Eles analisaram as estruturas de controle direta e indireta e encontraram alto grau de concentração de controle nas empresas. A concentração ocorre principalmente com a violação da regra uma ação um voto, por meio da utilização de ações sem direito a voto. Eles sugerem que a estrutura em forma de pirâmide, embora ampla, parece não ter como objetivo principal a separação de controle e propriedade.

Neste trabalho, analisaremos a estrutura de controle de empresas brasileiras, a partir de uma análise da concentração direta e indireta dos direitos sobre voto e fluxo de caixa dos acionistas controladores no final de 1998. A próxima seção descreve a amostra e a metodologia utilizada nos testes, incluindo a forma de medição dos direitos sobre os votos e sobre o fluxo de caixa. Segue uma análise da composição acionária direta das companhias brasileiras e da utilização de ações sem direito a voto como forma de financiamento. Em seguida, analisa-se a composição acionária indireta, bem como a utilização da estruturas piramidais por empresas brasileiras. A última seção conclui o trabalho.

\section{Dados e Metodologia}

Utilizamos uma amostra das companhias listadas na Bolsa de Valores de São Paulo (BOVESPA) que não são controladas pelo governo. Foram coletadas informações sobre a composição acionária das empresas no banco de dados do Infoinvest (Browne Global Solutions). As companhias de capital aberto têm por obrigação emitir o Informativo Anual para a CVM antes do final do primeiro semestre, relativo ao ano fiscal anterior. Este relatório deve fornecer, entre outras informações, a composição do capital da empresa. Foram utilizados os informativos anuais enviados no primeiro semestre de 1999, relativos ao ano de 1998.

A amostra inclui instituições financeiras e não-financeiras, excluindo as empresas sem informações disponíveis ou incompletas. A amostra final consiste em 225 firmas não controladas pelo governo que representam aproximadamente 70\% da capitalização de mercado total da BOVESPA e mais de 90\% da capitalização das empresas não controladas pelo governo na BOVESPA. Foram analisadas duas formas de composição acionária: a direta e a indireta. Acionistas diretos são aqueles que possuem ações da própria companhia. Foram considerados todos os acionistas com mais de 5\% do capital votante, uma vez que este é o limite para identificação obrigatória dos acionistas no Brasil. A composição indireta diz res- 
peito a acionistas que detêm a propriedade da empresa em última instância. Por exemplo, se um acionista possui $51 \%$ dos votos de uma companhia holding que detém 51\% dos votos de uma companhia de capital aberto, o acionista é o controlador da companhia aberta com $26 \%$ do capital votante da companhia aberta (51\% multiplicados por 51\%).

Um exemplo desta situação era encontrado na composição acionária das Lojas Americanas. Diretamente, a companhia tinha apenas um grande acionista (que possuía mais de $5 \%$ do capital votante), a empresa Varbra S.A., que era dona de $48,11 \%$ do capital votante e 18,06\% do capital total. Esta empresa, por sua vez, era controlada por três acionistas, com 50,28\%, 11,13\% e 11,13\% do capital votante e $35,16 \%, 12,85 \%$ e $12,85 \%$ do capital total cada um. Em outras palavras, as Lojas Americanas tinha indiretamente três acionistas em 1998, com o maior possuindo $24,19 \%$ (50,28\% vezes $48,11 \%)$ do capital votante e $6,35 \%$ (35,16\% vezes $18,06 \%)$ do capital total.

Esta análise foi possível, uma vez que o Informativo Anual também apresenta a composição acionária das companhias holding. Desta forma, a composição acionária foi analisada para trás até que fosse possível classificar os verdadeiros proprietários em um dos seguintes grupos: indivíduos, bancos, companhias de seguros, fundos de pensão, empregados, estrangeiros (tanto indivíduos como instituições), governo, fundações ou fundos de investimento.

As 225 empresas da amostra foram divididas em dois grupos: firmas com acionista majoritário e firmas sem acionista majoritário. Uma empresa possui acionista majoritário, quando um único acionista possui diretamente mais de 50\% do capital votante. Para a composição acionária direta e indireta foram computados o capital votante e o capital total que o maior acionista, os três maiores e os cinco maiores possuíam de cada companhia. Em seguida, foram calculadas as médias e medianas do capital votante e total que o maior, os três maiores e os cinco maiores acionistas detinham para os dois grupos.

A Figura 1 apresenta a divisão da amostra nos diversos grupos de análise utilizados. Primeiramente, as companhias com um acionista controlador foram separadas entre aquelas que apresentam uma estrutura indireta de controle e as que não apresentam uma estrutura indireta de controle. Depois separamos as companhias com estrutura indireta de controle em empresas onde o acionista mantém o controle indiretamente e empresas onde o controle não é mantido indiretamente. Para estas companhias, o controle não é mantido pelo mesmo acionista em algum nível da pirâmide, isto é, não há um acionista com mais de $50 \%$ dos votos em todos os níveis. Um exemplo desta situação era a composição acionária indireta da Inepar S.A. Indústria e Comércio. Embora, no primeiro nível, uma 
companhia (a Inepar Administração e Participações S.A.) tivesse uma parcela de $60,68 \%$ do capital votante, esta última tinha cinco acionistas sem um controlador único. Neste caso, diz-se que não há controle indireto, já que, na seqüência, nenhum acionista detinha mais de 50\% do capital votante.

\section{Figura 1}

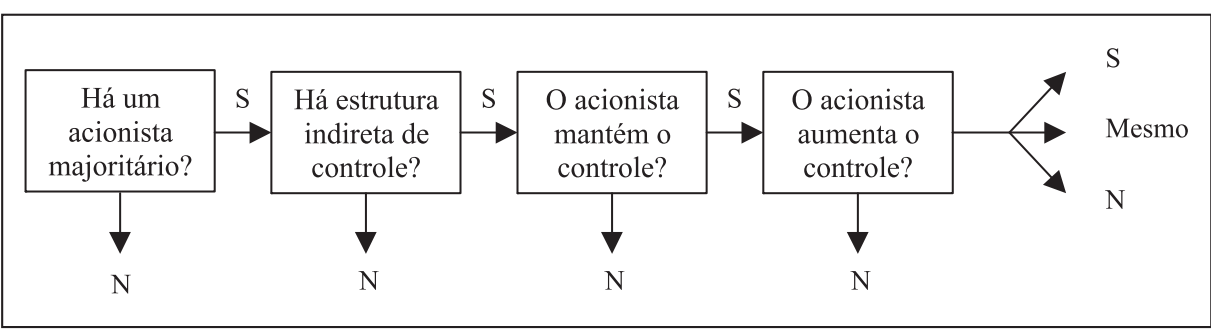

As companhias que possuem um acionista controlador indireto foram classificadas em três subgrupos: com concentração de capital, isto é, indiretamente o acionista controlador tem uma participação maior do que diretamente, com manutenção de participação e, por fim, com redução da participação do capital. Um exemplo de concentração de capital era o da empresa Construções Camargo Corrêa S.A. Isto ocorre porque um acionista pessoa física, além de ser proprietário direto de ações da empresa, também é dono de quase todo o capital das empresas que são as outras acionistas diretas da Camargo Corrêa.

Na empresa Dana Albarus S.A. Indústria e Comércio era possível ver um caso de manutenção do controle e da participação. A controladora indireta, Dana Corporation, detinha 100\% do capital da controladora direta, a Dana Equipamentos Ltda. Assim sendo, ela controlava a companhia com a mesma proporção do capital.

O último subgrupo é o das companhias onde há manutenção de controle por um acionista que indiretamente possui uma proporção do capital menor que diretamente. Como exemplo, pode-se tomar a própria Lojas Americanas. Neste caso, o controle era mantido com $24,19 \%$ do capital votante e apenas 6,35\% do capital total. A estrutura de pirâmide permite ao controlador alavancar a sua posição. O mínimo necessário para manter o controle de uma companhia, sem recorrer à estrutura de pirâmide, é 16,7\% do capital total (tendo apenas mais que 50\% do capital votante, respeitando o limite legal mínimo de um terço do capital total). No Brasil, é permitido às companhias emitir ações sem direito a voto numa quantidade de até dois terços do seu capital total. Isto permite às empresas emitir ações 
sem renunciar ao controle, sendo, então, uma forma de separar controle e propriedade. O controle de uma companhia pode ser garantido com apenas um sexto do seu capital total. Por conseguinte, este grupo pode representar as companhias onde a estrutura piramidal é usada para separar propriedade e controle, ou para se distanciar da regra de uma ação - um voto.

\section{Composição Acionária Direta}

A Tabela 1 mostra a estrutura de controle das empresas brasileiras no final de 1998. Os resultados apresentados são muito semelhantes aos encontrados por Valadares e Leal (2000) para o ano de 1996. Das 225 empresas, 155 (69\%) têm um único acionista que possui mais de $50 \%$ do capital votante. Esse acionista possui uma média de $74 \%$ do capital votante, muito perto da mediana de $75 \%$. Entre as companhias onde o controle não está nas mãos de um único acionista (70), o maior acionista possui, em média, 31\% do capital votante, com mediana de $30 \%$. Isso demonstra que, mesmo quando um único acionista não tem a maioria dos votos, o maior acionista possui uma parcela considerável deles. Considerando a amostra como um todo, o maior acionista, os três maiores e os cinco maiores possuem, em média, $61 \%$, $79 \%$ e $84 \%$ do capital votante, respectivamente.

Tabela 1: Composição Acionária Direta das Companhias Composição Acionária Direta Média (Mediana) de 225 Companhias Brasileiras Listadas na Bolsa de Valores de São Paulo no Final de 1998

\begin{tabular}{|c|c|c|c|c|c|c|}
\hline \multirow[b]{2}{*}{ Acionista } & \multicolumn{2}{|c|}{$\begin{array}{c}\text { Companhias com um } \\
\text { acionista majoritário } \\
\text { (155) }\end{array}$} & \multicolumn{2}{|c|}{$\begin{array}{c}\text { Companhias sem um } \\
\text { acionista majoritário } \\
\text { (70) }\end{array}$} & \multicolumn{2}{|c|}{$\begin{array}{c}\text { Total da } \\
\text { Amostra } \\
(225)\end{array}$} \\
\hline & $\begin{array}{l}\text { Capital } \\
\text { Votante }\end{array}$ & $\begin{array}{c}\text { Capital } \\
\text { Total }\end{array}$ & $\begin{array}{l}\text { Capital } \\
\text { Votante }\end{array}$ & $\begin{array}{c}\text { Capital } \\
\text { Total }\end{array}$ & $\begin{array}{l}\text { Capital } \\
\text { Votante }\end{array}$ & $\begin{array}{c}\text { Capital } \\
\text { Total }\end{array}$ \\
\hline Maior & $\begin{array}{c}74 \% \\
(75 \%)\end{array}$ & $\begin{array}{c}53 \% \\
(50 \%)\end{array}$ & $\begin{array}{c}31 \% \\
(30 \%)\end{array}$ & $\begin{array}{c}22 \% \\
(18 \%)\end{array}$ & $\begin{array}{c}61 \% \\
(59 \%)\end{array}$ & $\begin{array}{c}43 \% \\
(37 \%)\end{array}$ \\
\hline 3 Maiores & $\begin{array}{c}86 \% \\
(89 \%)\end{array}$ & $\begin{array}{c}62 \% \\
(60 \%)\end{array}$ & $\begin{array}{c}65 \% \\
(69 \%)\end{array}$ & $\begin{array}{c}44 \% \\
(43 \%)\end{array}$ & $\begin{array}{c}79 \% \\
(84 \%)\end{array}$ & $\begin{array}{c}56 \% \\
(55 \%)\end{array}$ \\
\hline 5 Maiores & $\begin{array}{l}87 \% \\
(90 \%)\end{array}$ & $\begin{array}{c}62 \% \\
(62 \%)\end{array}$ & $\begin{array}{c}76 \% \\
(78 \%)\end{array}$ & $\begin{array}{c}49 \% \\
(48 \%)\end{array}$ & $\begin{array}{c}84 \% \\
(88 \%)\end{array}$ & $\begin{array}{c}58 \% \\
(59 \%)\end{array}$ \\
\hline
\end{tabular}


Nossos resultados mostram um alto grau de concentração do capital votante. Mesmo quando não existe um acionista majoritário, o maior acionista possui uma parcela significativa do capital votante. A empresa é controlada, na média, por seus três maiores acionistas. Além disso, 84\% do capital votante das empresas está nas mãos dos cinco maiores acionistas. Também podemos notar uma diferença razoável entre o percentual de votos e de capital total nas mãos dos grandes acionistas. Isso permite que empresas emitam ações sem abrir mão do controle e é, portanto, um meio de separar propriedade e controle. Esse mecanismo parece ser usado pelos grandes acionistas para manter o controle da empresa, sem ter que possuir 50\% do capital total. Em empresas com um único acionista majoritário, este possui uma média de 74\% do capital votante, mas apenas 53\% do capital total. Considerando a amostra inteira, os cinco maiores acionistas possuem $84 \%$ do capital votante, mas apenas 58\% do capital total. Como ressaltam Valadares e Leal (2000) para o ano de 1996, se existe alguma diluição na propriedade da empresa, isso ocorre por meio de ações sem direito a voto. A emissão de ações sem direito a voto permite a manutenção do controle com uma participação menor no capital da empresa, levando à separação entre propriedade e controle.

\section{Composição Acionária Indireta}

A Tabela 2 mostra a estrutura indireta de controle de empresas brasileiras no final de 1998. Nossos resultados revelam que nas empresas onde o maior acionista possui mais de 50\% do capital votante diretamente, a propriedade indireta é mais diluída. Na forma direta, o acionista majoritário possui, em média, 74\% do capital votante e $53 \%$ do total, enquanto indiretamente as participações são de, respectivamente, 55\% e 37\%. Por outro lado, essa redução na participação do maior acionista não ocorre em empresas onde não existe um acionista majoritário. Pelo contrário, os dados mostram um pequeno aumento no capital investido para estes casos. Este fato pode indicar a utilização de estruturas piramidais para manter o controle com investimento reduzido na empresa. Se essa estrutura piramidal ocorre em alguns níveis, a separação entre propriedade e controle e também o afastamento da regra uma ação - um voto torna-se ainda maior. 


\section{Tabela 2: Composição Acionária Indireta das Companhias Composição Acionária Indireta Média (Mediana) de 225 Companhias Brasileiras Listadas na Bolsa de Valores de São Paulo no Final de 1998}

\begin{tabular}{|c|c|c|c|c|c|c|}
\hline \multirow[b]{2}{*}{ Acionista } & \multicolumn{2}{|c|}{$\begin{array}{c}\text { Companhias com um } \\
\text { acionista majoritário } \\
\text { (155) }\end{array}$} & \multicolumn{2}{|c|}{$\begin{array}{c}\text { Companhias sem um } \\
\text { acionista majoritário } \\
\text { (70) }\end{array}$} & \multicolumn{2}{|c|}{$\begin{array}{c}\text { Total da } \\
\text { Amostra } \\
\text { (225) }\end{array}$} \\
\hline & $\begin{array}{l}\text { Capital } \\
\text { Votante }\end{array}$ & $\begin{array}{c}\text { Capital } \\
\text { Total }\end{array}$ & $\begin{array}{c}\text { Capital } \\
\text { Votante }\end{array}$ & $\begin{array}{c}\text { Capital } \\
\text { Total }\end{array}$ & $\begin{array}{c}\text { Capital } \\
\text { Votante }\end{array}$ & $\begin{array}{c}\text { Capital } \\
\text { Total }\end{array}$ \\
\hline Maior & $\begin{array}{l}55 \% \\
(54 \%) \\
\end{array}$ & $\begin{array}{c}37 \% \\
(31 \%) \\
\end{array}$ & $\begin{array}{c}34 \% \\
(29 \%) \\
\end{array}$ & $\begin{array}{c}23 \% \\
(18 \%) \\
\end{array}$ & $\begin{array}{c}48 \% \\
(47 \%) \\
\end{array}$ & $\begin{array}{c}33 \% \\
(26 \%) \\
\end{array}$ \\
\hline 3 Maiores & $\begin{array}{c}71 \% \\
(76 \%)\end{array}$ & $\begin{array}{c}48 \% \\
(45 \%)\end{array}$ & $\begin{array}{c}61 \% \\
(62 \%)\end{array}$ & $\begin{array}{c}40 \% \\
(37 \%)\end{array}$ & $\begin{array}{c}68 \% \\
(71 \%)\end{array}$ & $\begin{array}{c}46 \% \\
(43 \%)\end{array}$ \\
\hline 5 Maiores & $\begin{array}{c}75 \% \\
(79 \%)\end{array}$ & $\begin{array}{c}50 \% \\
(49 \%)\end{array}$ & $\begin{array}{c}70 \% \\
(74 \%)\end{array}$ & $\begin{array}{c}46 \% \\
(41 \%)\end{array}$ & $\begin{array}{c}73 \% \\
(78 \%)\end{array}$ & $\begin{array}{c}49 \% \\
(47 \%)\end{array}$ \\
\hline
\end{tabular}

Nós classificamos as 155 empresas nas quais existia um acionista controlador segundo os grupos mostrados na Tabela 3. O primeiro grupo é formado por empresas cujo controle não é mantido indiretamente, ou seja, não existe um único acionista com mais de 50\% do capital votante. Das 155 empresas, 53 estão nesse grupo (34\%). Em 68 empresas (44\%), observamos pirâmides com manutenção do controle; em todos os níveis, existe um acionista com mais de $50 \%$ do capital votante. Dividimos essas companhias em três subgrupos: aquelas onde há concentração de capital, com 15 empresas (10\%); aquelas onde a participação no capital é mantida, com 17 empresas (11\%); e aquelas onde a participação no capital é reduzida, com 36 empresas (23\%). Por fim, o último grupo é formado por empresas, onde as participações direta e indireta são idênticas - mesma participação e mesmo acionista. Essas são empresas que não utilizam estrutura piramidal. Existem 34 empresas nesse grupo (22\%).

Os dados na Tabela 3 parecem indicar que a utilização de pirâmide como um mecanismo de manutenção de controle de empresas a um custo menor, ou seja, com um investimento menor no capital total, não é muito comum. Das 121 empresas onde existe estrutura piramidal e onde as participações direta e indireta são diferentes, apenas 36 (30\%) têm um acionista que mantém o controle com redução no percentual de capital investido. Na média, enquanto o acionista majoritário garante o controle com $54 \%$ do capital total da empresa, indiretamente a participação média no capital é de 35\%. Em 53 empresas (44\%), o acionista majoritário não mantém o controle indiretamente. 


\section{Tabela 3: Participação Indireta dos Controladores}

\begin{tabular}{|c|c|c|c|c|c|}
\hline & & \multicolumn{2}{|c|}{$\begin{array}{c}\text { Participação } \\
\text { direta do } \\
\text { acionista } \\
\text { controlador }\end{array}$} & \multicolumn{2}{|c|}{$\begin{array}{c}\text { Participação } \\
\text { indireta do } \\
\text { acionista } \\
\text { controlador }\end{array}$} \\
\hline $\begin{array}{c}\text { Há estrutura } \\
\text { indireta? }\end{array}$ & $\begin{array}{c}\text { Acionista mantém } \\
\text { o controle? }\end{array}$ & $\begin{array}{c}\text { Capital } \\
\text { Votante }\end{array}$ & $\begin{array}{c}\text { Capital } \\
\text { Total }\end{array}$ & $\begin{array}{c}\text { Capital } \\
\text { Votante }\end{array}$ & $\begin{array}{c}\text { Capital } \\
\text { Total }\end{array}$ \\
\hline Sim & Não (53) & $75 \%$ & $54 \%$ & $26 \%$ & $16 \%$ \\
\hline & Sim - Concentração (15) & $64 \%$ & $40 \%$ & $81 \%$ & $51 \%$ \\
\cline { 2 - 6 } & Sim - Manutenção (17) & $74 \%$ & $52 \%$ & $74 \%$ & $52 \%$ \\
\cline { 2 - 6 } & Sim - Diversificação (36) & $77 \%$ & $54 \%$ & $59 \%$ & $35 \%$ \\
\cline { 2 - 6 } & Sim - Todos (68) & $73 \%$ & $50 \%$ & $68 \%$ & $43 \%$ \\
\cline { 2 - 6 } & Média Sim e Não & $74 \%$ & $52 \%$ & $50 \%$ & $31 \%$ \\
\hline \multirow{2}{*}{ Não (34) } & Mesma composição & $74 \%$ & $56 \%$ & $74 \%$ & $56 \%$ \\
\hline
\end{tabular}

Nota: as companhias que possuem um acionista com mais de $50 \%$ do capital votante foram classificadas em 5 grupos, analisando-se a participação indireta do controlador.

A utilização de estrutura piramidal não parece ser um esforço para evitar a regra uma ação - um voto em empresas brasileiras. A legislação brasileira permite que se tenha o controle direto da companhia com 16,7\% do capital total direto. Indiretamente, esse número poderia ser ainda menor. Não é isso o que a Tabela 3 mostra. A participação indireta no capital total do acionista controlador em média é de $43 \%$, quando ele mantém o controle indiretamente, e de $16 \%$, mesmo quando ele não mantém o controle. A participação no capital votante também é bem mais alta que 50\% na maioria dos casos, mesmo indiretamente.

\section{Conclusões}

O objetivo deste trabalho foi analisar a estrutura de controle e propriedade das companhias brasileiras de capital aberto. Foram analisadas 225 companhias brasileiras, listadas na BOVESPA, que não são controladas pelo governo no final de 1998. A amostra incluiu tanto instituições financeiras como não-financeiras e excluiu todas as companhias, cujos dados eram incompletos ou não estavam disponíveis. Nossos resultados revelam um elevado grau de concentração de capital votante em 1998. Mesmo nos casos em que não há um acionista controlador, o maior acionista detém uma participação significativa dos direitos sobre voto e a companhia é, geralmente, controlada por seus três maiores acionistas. 
É possível observar também uma diferença significativa entre a participação no capital votante e no capital total por parte dos grandes acionistas. Concluímos também que a utilização de pirâmides como um mecanismo para manutenção de controle a um custo menor, isto é, com um investimento menor no capital total, não é muito comum. Os acionistas controladores brasileiros investem em média muito mais do que o mínimo necessário para manter o controle nas suas companhias. A utilização da estrutura de pirâmides não parece ser um esforço no sentido de evitar a regra de uma ação - um voto nas companhias brasileiras.

Uma das explicações para a redução do investimento na companhia seria os benefícios privados de controle, que permitiriam a expropriação do acionista minoritário; entretanto, como os acionistas controladores detêm uma porção significativa do capital total, expropriar os minoritários abertamente levaria a uma redução do patrimônio dos controladores por meio da desvalorização de suas ações sem direito a voto. Valadares (1998) demonstrou que o prêmio de controle no Brasil pode chegar a mais de $150 \%$ do valor das ações sem direito a voto em transações de transferência de controle fora da bolsa de valores. Então, ou os benefícios privados de controle, dimensionados pelo prêmio de controle, são de tal magnitude que superam a desvalorização das ações sem direito a voto devido à expropriação dos acionistas minoritários, ou não há benefícios privados de controle significativos. A segunda alternativa é muito pouco provável diante dos resultados apresentados por Valadares (1998). É possível que os acionistas controladores detenham uma parcela relevante de ações sem direito a voto por conta da liquidez que oferecem. Por exemplo, Saito (2000) mostra que o valor das ações preferenciais na bolsa em geral é maior do que o valor das ações ordinárias e que o fator mais importante para explicar tal diferença é a maior liquidez das ações preferenciais. Diante das evidências apresentadas neste e em outros trabalhos revistos, preferimos concluir que os benefícios privados de controle no Brasil são expressivos. Ainda assim, os controladores detêm ações sem direito a voto. As razões podem ser que elas constituam parte da sua compensação como executivos da empresa, uma vez que podem ser vendidas com facilidade, sem alterar a composição do controle da empresa. Fica para pesquisas posteriores investigar as razões para que um controlador possua uma parcela importante de ações sem direito a voto, mesmo quando seus atos afetam negativamente o seu valor, e se o valor da firma é menor quando há maior concentração do poder de voto, como evidência indireta de expropriação. 


\section{ReferênCias Bibliográficas}

BERLE, A.;

MEANS, G.

The modern corporation and private property. New York: MacMillan, 1932.

HALLQVIST, B.

Código das melhores práticas de governança corporativa: o conselho de administração. Revista de Administração, v. 35, n. 2, p. $72-$ 76, 2000.

\section{LA PORTA, R. et al.}

Law and finance. Journal of Political Economy, v. 106, p. 1113-1155, 1998.

Corporate ownership around the world. Journal of Finance, v. 54, p. 471-518, 1999.

PROCIANOY, J. L.

O processo sucessório e a abertura de capital nas empresas brasileiras: objetivos conflitantes. Revista de Administração de Empresas, v. 34, n. 4, p. 74-84, 1994.

PROCIANOY, J.;

COMERLATO, G.

Proposta de um método para verificação de evidências de transferência de lucro entre empresas similares abertas de um mesmo grupo econômico. In: ENCONTRO ANUAL DA ANPAD,
XVIII, 1994, Curitiba. Anais... Curitiba: ANPAD, 1994. p. 249264.

SAITO, R.

Determinants of differential pricing of equity classes in the Brazilian equity market. In: ENCONTRO ANUAL DA ANPAD, XXIV, 2000, Florianópolis. Anais... Florianópolis: ANPAD, 2000. 1 CD-ROM.

SIFFERT FILHO, N.

Governança corporativa: padrões internacionais e evidências empíricas no Brasil nos anos 90. Revista do BNDES, n. 9, 1998.

SIQUEIRA, T.

Concentração da propriedade nas empresas brasileiras de capital aberto. Revista do BNDES, n. 10, 1998.

VALADARES, S.

Três ensaios sobre mercado por controle no Brasil. Rio de Janeiro, 1998. Tese (Doutorado em Economia) - Departamento de Economia, Pontifícia Universidade Católica do Rio de Janeiro.

VALADARES, S.;

LEAL, R.

Ownership and control structure of Brazilian companies. Revista Abante, v. 3, n. 1, p. 29-56, 2000. 